\title{
Characteristics of micro- and nano-pores in shale oil reservoirs
}

\author{
Debin $\mathrm{Xia}^{1} \cdot$ Zhengming Yang ${ }^{2} \cdot$ Tiening Gao ${ }^{1} \cdot$ Haibo $\mathrm{Li}^{2} \cdot$ Wei $\mathrm{Lin}^{3}(\mathrm{C}$
}

Received: 20 June 2020 / Accepted: 20 September 2020 / Published online: 7 October 2020

(c) The Author(s) 2020

\begin{abstract}
Porosity is the most common form of reservoirs, and its size, shape, and connectivity directly affect the capacity of oil and gas storage and production. To study the micro-nano-pore structure characteristics of shale oil reservoirs and quantitatively characterize its heterogeneity, this work uses high-precision high-pressure mercury intrusion (HPMI) experimental techniques to study the micro-nano-pore structure characteristics of shale oil, and based on the experimental data, fractal theory is used to quantitatively characterize its heterogeneity. The results of the study show that the micro-nano-pores in the shale oil reservoir are concentrated and continuous, and the pore radius is mainly distributed among the range of 30-500 nm, nanoscale pores are an important part of the pores of the shale oil reservoir. The fractal dimension of the shale oil reservoir is larger than the fractal dimension of typical tight oil reservoirs, indicating that the heterogeneity of shale oil reservoir is stronger. The research results have some theoretical and practical significance for the production of inter-salt shale oil reservoirs.
\end{abstract}

Keywords Shale oil $\cdot$ Micro-nano $\cdot$ Pore structure $\cdot$ High-pressure mercury intrusion $\cdot$ Fractal

\section{List of symbols}

D Fractal dimension of shale oil core micro-nanopore volume

$s \quad$ Intrusive mercury saturation of high-pressure mercury intrusion experiment

$p \quad$ Pressure of high-pressure mercury intrusion, i.e., capillary pressure

$P_{\min } \quad$ Capillary pressure corresponding to the maximum pore diameter

\section{Abbreviations}

CT Computed tomography

NMR Nuclear magnetic resonance

LTNA Low-temperature nitrogen adsorption

HPMI High-pressure mercury injection

Zhengming Yang

yzhm69@petrochina.com.cn

Wei Lin

ucaslinwei@126.com

1 Institute of Porous Flow and Fluid Mechanics, University of Chinese Academy of Sciences, Langfang 065007, China

2 Department of Porous Flow and Fluid Mechanics, Research Institute of Petroleum Exploration and Development, PetroChina Company Limited, Beijing 100083, China

3 School of Geosciences, Yangtze University, Wuhan 430100, China

\section{Introduction}

Since 2010, some scholars have carried out large-scale research in the unconventional oil and gas field and gradually formed an unconventional oil and gas geological theory system (Zou et al. 2012b). As the shale gas revolution in North America, with the shale gas development experience and the technology of horizontal well volume fracturing, China has made gratifying progress in the field of tight oil and shale gas and has achieved breakthroughs in Ordos, Songliao, Zhungeer, Bohai Bay and Sichuan basin and other basins ( $\mathrm{Li}$ et al. 2015). According to the hydrocarbon generation theory, shale oil reservoirs with source retention of 20-50\% show great potential for oil and gas development. In this context, Zou et al. believed that breaking through the shale oil mining technology and turning it into production is the goal of future oil exploration and development (Zou et al. 2012a).

Reservoir engineers and geologists can accurately predict recoverable oil and gas reserves and optimize their production only by understanding the reservoir pore structure (Butcher and Lemmens 2011; Didar and Akkutlu 2013; Kou et al. 2016). The complex pore structure of unconventional reservoirs is an important factor affecting reservoir properties and hydrocarbon storage; therefore, the study of pore structure is key points of oil and gas development research in unconventional petroleum field (Shen et al. 2019; Zhao et al. 2019). The pores of Barnett shale in the Mississippian Basin 
range from 5 to $750 \mathrm{~nm}$, with an average of $100 \mathrm{~nm}$ (Loucks et al. 2009). The Barnett shale in the Mississippian Basin has a pore size range of 5 to $750 \mathrm{~nm}$, with an average of $100 \mathrm{~nm}$, while the shale in the $\mathrm{J}$ Basin in China has a smaller pore size range of $4-40 \mathrm{~nm}$. It is a semi-salinized lake source rock and has high salinity and strongly formed in an evaporative environment, it has a good seasonal rhythmic layer, and the lithology is diverse, including mudstone, glauberite shale, dolomitic mudstone, etc. (Loucks et al. 2009; Jia et al.,2012; Zou et al. 2012a, b; Demaison and Moore 1980). Mud shale reservoirs are mostly micro- and nanoscale pores with strong heterogeneity. The micropore structure is the key factor that determines the pore-percolation relationship and fluid storage and migration (Slatt and O'Brien 2011; Kuila and Prasad 2013). At present, the technical methods for studying the pore structure of conventional reservoirs mainly include scanning electron microscopy, analysis of cast thin sections, and computed tomography (CT) scanning. The average pore size of shale oil is only on the nanometer scale, and conventional methods obviously cannot effectively describe the pore structure characteristics of shale. When measuring the pore size using scanning electron microscopy method, human factors have a relatively large influence, and its application is limited, and only the local pore shape can be observed, and the statistical representativeness is poor. Due to the limitation of the low resolution of the optical microscope, casting thin film analysis is usually only used to observe conventional micro-nano-level pores (Zhong 2012). Bai et al. (2013) used micro-nano multi-scale CT technology to conduct three micro-imaging studies on tight sandstone reservoirs and clarified the structural characteristics of tight sandstone micropore shapes, sizes, spatial distribution, and connectivity. But the maximum resolution of ordinary CT and micro-CT is $0.25 \mathrm{~mm}$ and $0.7 \mu \mathrm{m}$, and it is impossible to observe nanoscale pores in shale reservoirs. The maximum resolution of nano-CT is $50 \mathrm{~nm}$, and it is still impossible to observe the pores of the shale oil reservoir of a pore size range of $4-40 \mathrm{~nm}$, and the sample size is extremely small, with a diameter of only $65 \mu \mathrm{m}$, which has strong randomness and cannot completely observe shale oil storage layer pore structure.

The main experimental methods of studying the pore structure characteristics of shale oil reservoirs include nuclear magnetic resonance (NMR), low-temperature nitrogen adsorption (LTNA), and high-pressure mercury injection (HPMI). Although NMR can measure any tiny pore signal and maintain the integrity of the sample, this method is an indirect pore structure testing technique, it is impossible to directly draw an accurate conclusion of the pore size distribution from the $\mathrm{T} 2$ spectrum, and it needs to be compared with the capillary pressure curve. Compare the pore size distribution corresponding to the $\mathrm{T} 2$ spectrum $(\mathrm{Li}$ et al. 2008), and also magnetic minerals and temperature have a great influence on the measurement results of the NMR T2 spectrum; the relative error increases with the increase in magnetic materials and temperature difference. Magnetic metal minerals, especially pyrite, are widespread in shale reservoirs (Liu et al. 2017; Chen et al. 2018). Clay minerals in shale have a certain adsorption capacity for gas, leading to the distribution of pore-throat radius determined through LTNA that has a large jump, and the truly effective pore-throat size range is limited (Zhong 2012; Zhao et al. 2019). Washburn proposed a capillary method for the determination of the pore structure of porous materials by the mercury intrusion method (Washburn 1921). The maximum mercury inlet pressure on conventional mercury intrusion is relatively small, which is unable to break through the capillary pressure in the nanoscale of shale and cannot effectively describe the nanoscale pore structure of shale, so it cannot measure pores below $15 \mathrm{~nm}$ (Sun et al. 2017). HPMI has a maximum mercury inlet pressure of $413.8 \mathrm{MPa}$, and the smallest pore diameter that can be tested is about $2 \mathrm{~nm}$, which can reflect more pore structure characteristics. HPMI experiments have been widely used in the study of pore structure characteristics of conventional reservoirs and have been applied well in reservoirs such as tight sandstones, so they are applied to the study of the pore structure of shale oil reservoirs (Fishman et al. 2012; Wang et al. 2016; Curtis et al. 2010; Labani et al. 2013; Clarkson et al. 2013; Gong et al. 2015; Yang et al. 2013). The fractal theory proposed by the famous French mathematician Mandelbrot provides a scientific method for describing the irregularity of shale pore distribution. Many scholars have studied the fractal characteristics of pore structure in rocks and pointed out that the pore distribution has statistical self-similarity and introduced the fractal dimension to describe the distribution characteristics of pores (Katz and Thompson 1985; Krohn 1988; Wei et al. 2015). The fractal dimension can not only describe shale. The pore size and distribution are uniform, and it can describe the complexity of shale pore morphology. Therefore, the fractal dimension has become an important parameter for the quantitative description of the shale pore structure, and it can be used to quantitatively characterize shale reservoir heterogeneity.

Through previous literature surveys, it is found that there are several problems with the study of shale pore structure: (1) The experimental methods used are not accurate enough to describe the characteristics of the nanopore structure of shale reservoirs; (2) the measured pore space contains non-connected pores, and the oil and gas in these pores cannot be exploited and are considered invalid pores; (3) the heterogeneity of shale oil reservoirs is only a qualitative description without quantitative characterization. In this study, we use high-pressure mercury intrusion experiment technology to conduct in-depth research on the micro-nano-pore structure characteristics of shale 
reservoirs, analyze the micro-nano-pore throat distribution, and compare it with typical domestic tight oil reservoirs. Based on the experimental data, the fractal theory was used to quantitatively characterize the heterogeneity of shale oil reservoirs, laying a foundation for the development of shale oil reservoirs.

\section{Experimental principle and sample}

\section{Experimental principle}

When the non-wet phase is injected into the porous medium, the surface tension prevents the non-wet phase from entering the pores, and additional pressure is required to inject the non-wet phase liquid into the rock pores. This additional pressure is equal to the capillary pressure. When the capillary pressure is measured by the mercury intrusion method, mercury is injected into the rock pores as a non-wet phase, and the injection amount corresponds to the pore volume of the pore throat in a porous medium. When the rock samples reach the pressure equilibrium at each pressure point, the change of the amount of mercury introduced with the change of the injection pressure is measured. The recorded results are plotted to obtain the rock capillary pressure curve measured by the mercury intrusion method (Sing 1985). The main advantage of the HPMI experiment is that the maximum mercury inlet pressure is large enough (up to $413.8 \mathrm{MPa}$ ), and it can test smaller pores. (The minimum test pore size is about $2 \mathrm{~nm}$.) The capillary pressure curve obtained by the mercury intrusion method can provide information on the microscopic pore structure of the reservoir. On the one hand, the shape of the curve itself can help research on the pore structure type and sortability of the reservoir; on the other hand, the measured parameters can also provide information including the throat radius and its distribution, throat sorting and homogeneity, a large number of reservoir characteristic parameters, such as rock storage and permeability, availability of rock fluids, and degree of tortuous bends in pore throats.

HPMI tests were conducted by using the PoreMaster 60 HPMI following the SY/T 5346-2005 standard, as shown in Fig. 1. The measuring range of the pore size distribution of this instrument is $950-0.0018 \mu \mathrm{m}$, and the pressure test range $20-60,000$ psi. The mercury feeding method adopts continuous mercury feeding. According to the capillary pressure curve, the characteristic parameters include discharge pressure, maximum pore throat radius, median value, median pressure radius, mean radius, mainstream throat radius, sorting coefficient, maximum mercury saturation, and mercury removal efficiency.

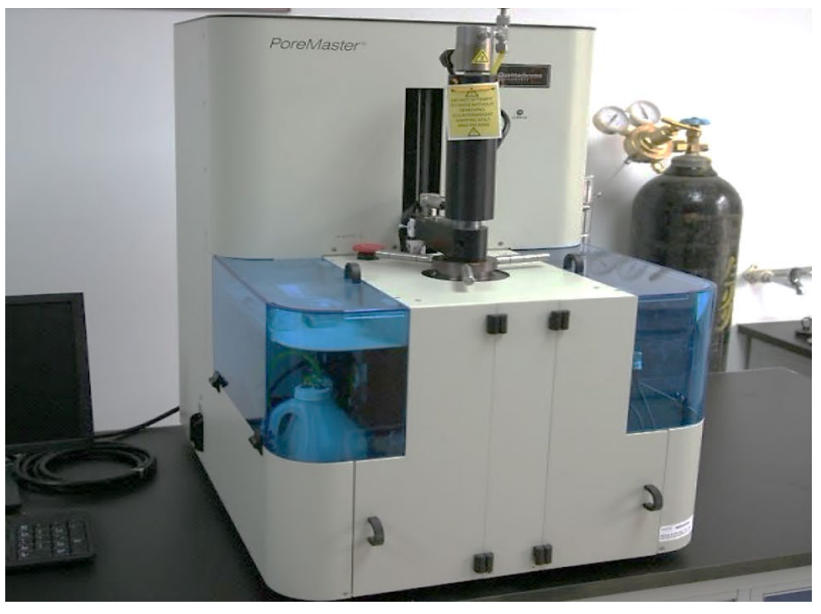

Fig. 1 PoreMaster 60 type of mercury pressure meter

\section{Sample}

The rock samples of the experiment are all from the third member of the Qianjiang Sag shale in the J Basin, China. Pores are the most common form of existence in reservoirs, and their size and connectivity directly affect the production capacity of oil and gas. During the formation of pores, different mineral components have a greater impact on the pore structure and type. Through literature review, we get the comparison of the mineral composition of the $\mathrm{J}$ Basin and other shale oil reservoirs as shown in Fig. 2:

Figure 2 shows that the Shale oil reservoirs in the Qianjiang Sag of the J Basin have relatively low quartz and clay mineral content, while the opposite carbonate and brittle mineral content are relatively high; this provides favorable conditions for the exploration and development of the shale oil reservoir.

To further study the pore structure characteristics of this block of the reservoir, we selected four typical rock samples in the $\mathrm{J}$ Basin and analyzed the mineral composition using $\mathrm{X}$-ray diffraction technology, the analysis results, and basic core data which are shown in Table 1 and Table 2.

Tables 1 and 2 show the pore permeability data and mineral composition of the cores of four shale oil reservoirs. These two tables show that: (1) these four shale oil cores contain the highest carbonate minerals (range 40.2-61.6\%, average $53.5 \%$ ), followed by clay minerals (range $18.9-21.3 \%$, average $19.9 \%$ ), again quartz (range $7.8-18.1 \%$, average $11.7 \%$ ), and evaporative minerals (range 6.1-15.3\%, average 10\%), and the lowest feldspar content (average is less than 5\%); (2) the core layer porosity is large and uniform, and the average porosity is $18.44 \%$; the porosity has a good correlation with dolomite; (3) the gas permeability of the four cores is similar, and the Klinkenberg permeability is about half of the gas permeability. The relationship between

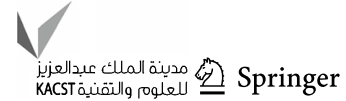




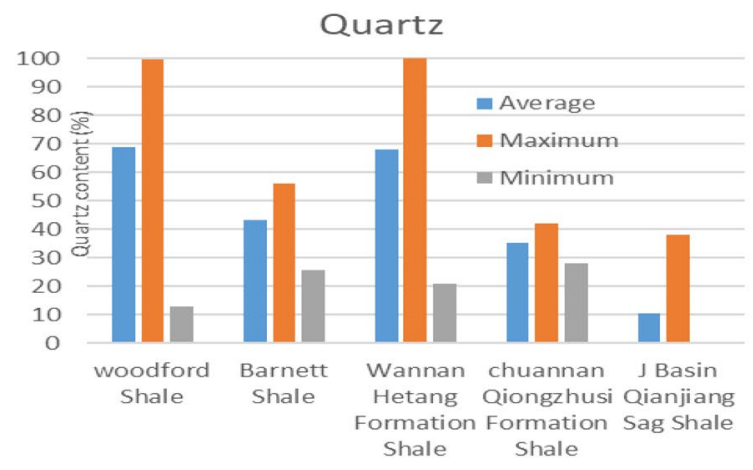

(a)

carbonate

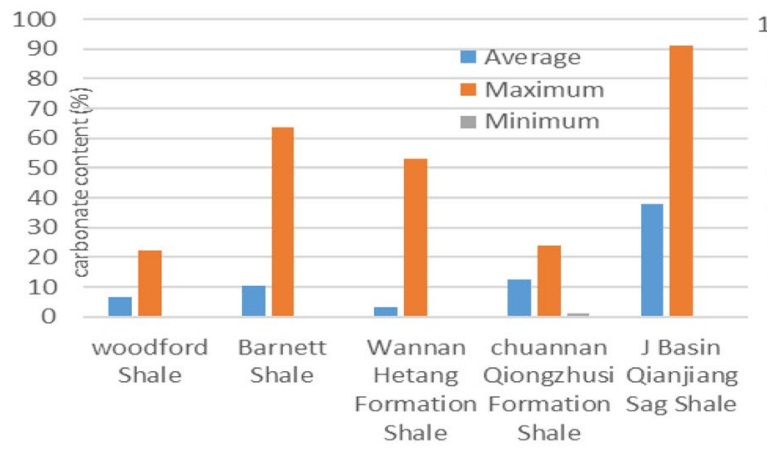

(c)

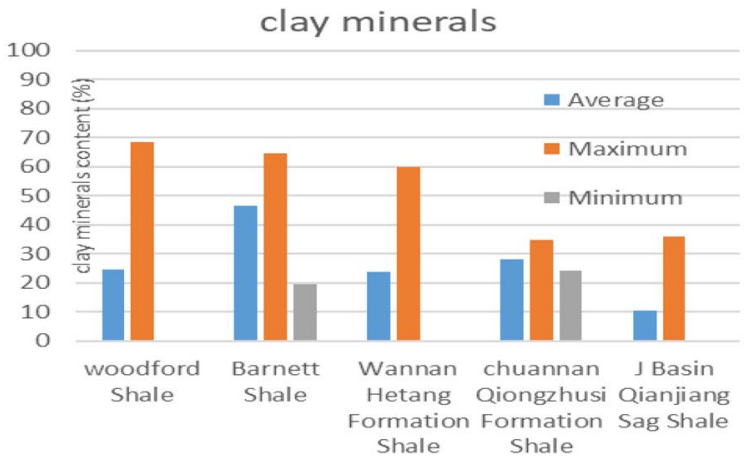

(b)

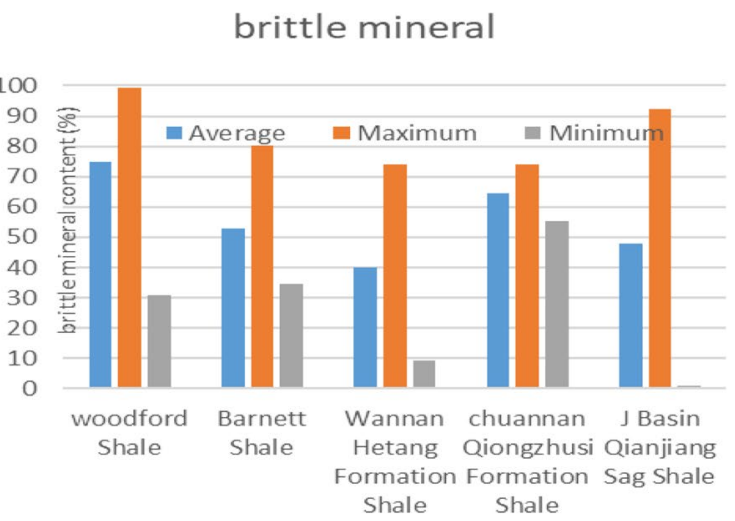

(d)

Fig. 2 Comparison of mineral composition of shale reservoirs in different blocks. Data sources: Jarvie et al. (2007), Zhao et al. (2014), Zhang et al. (2015)

Table 1 Core mineral composition

\begin{tabular}{|c|c|c|c|c|c|c|c|c|c|c|}
\hline \multirow[t]{2}{*}{ No. } & \multicolumn{3}{|c|}{ Clay minerals } & \multirow[t]{2}{*}{ Quartz } & \multirow[t]{2}{*}{ Feldspar } & \multicolumn{2}{|c|}{ Carbonate minerals } & \multicolumn{2}{|c|}{ Evaporite minerals } & \multirow[t]{2}{*}{ Brittle minerals } \\
\hline & Illite & Chlorite & $\begin{array}{l}\text { Mony mixed } \\
\text { layer }\end{array}$ & & & Dolomite & Calcite & Plaster & Glauberite & \\
\hline l & $\%$ & $\%$ & $\%$ & $\%$ & $\%$ & $\%$ & $\%$ & $\%$ & $\%$ & $\%$ \\
\hline 1 & 12.8 & 0.5 & 5.9 & 7.8 & 5.3 & 53.7 & 7.9 & 1.6 & 4.5 & 74.7 \\
\hline 2 & 12.7 & 1.0 & 5.2 & 18.1 & 7.5 & 31.3 & 8.9 & 3.2 & 12.1 & 65.8 \\
\hline 3 & 17.3 & 0.0 & 4.0 & 12.3 & 3.4 & 44.3 & 9.2 & 2.3 & 7.2 & 69.2 \\
\hline 4 & 14.8 & 0.9 & 4.4 & 8.5 & 3.6 & 50.2 & 8.5 & 1.8 & 7.3 & 70.8 \\
\hline
\end{tabular}

Table 2 Core data and pore permeability

\begin{tabular}{lllllllll}
\hline No. & Lithology & Length & Dia. & Dry weight & Density & Porosity & Permeability & $\begin{array}{l}\text { Klinkenberg } \\
\text { permeability } \\
1\end{array}$ \\
& / & $\mathrm{cm}$ & $\mathrm{cm}$ & $\mathrm{g}$ & $\mathrm{g} / \mathrm{cm}^{3}$ & $\%$ & $10^{-3} \mu \mathrm{m}^{2}$ & $10^{-3} \mathrm{~m}^{2}$ \\
\hline 1 & Dolomitic mudstone & 4.493 & 2.506 & 48.576 & 2.19 & 21.11 & 0.141 & 0.069 \\
2 & Dolomitic mudstone & 4.033 & 2.470 & 45.988 & 2.38 & 14.24 & 0.232 & 0.165 \\
3 & Dolomitic mudstone & 5.355 & 2.463 & 57.295 & 2.25 & 17.92 & 0.122 & 0.058 \\
4 & Dolomitic mudstone & 2.955 & 2.465 & 31.119 & 2.21 & 20.47 & 0.151 & 0.074 \\
\hline
\end{tabular}


porosity and permeability is poor, indicating that the core heterogeneity is strong; (4) the core contains high brittle minerals (including quartz, feldspar, and carbonate minerals), which has good brittleness and compressibility and provides favorable conditions for exploration (Wang et al. 2016). The shale oil reservoir has large porosity compared with other shale oil reservoirs, which is due to its dolomitic development, salt occurrences such as glauberite, providing physical conditions for the development of the reservoir shale oil (Chen and Zhao 2010; Wu et al. 2013).

\section{Experimental results and discussion}

\section{Shale oil reservoir micro-nano-pore distribution}

According to the previous studies, it is believed that nanoscale pores and micro-cracks are widely developed in general shale oil reservoirs and microscale pores are locally developed (Zhu et al. 2013). This study will analyze the pore throat distribution characteristics and the characteristics of permeability contribution rate according to the measured capillary pressure curve and related parameters (Guo et al. 2013).

The following introduces the definition and meaning of each parameter

(1) Displacement pressure and maximum pore throat radius

The pressure at which the non-wetting phase fluid begins to enter the maximum pore throat in the core or the minimum pressure at which the non-wetting phase begins to enter the core is called the displacement pressure, and the corresponding throat radius is the maximum pore throat radius.

\section{(2) Median pressure and median radius}

When the saturation of the non-wetting phase is 50\%, the capillary pressure corresponding to the corresponding injection curve is called the median saturation pressure, and the corresponding pore throat radius is called the median radius. The lower the median saturation pressure, the better the rock permeability and the higher the production capacity of the corresponding reservoir. The throat radius corresponding to the median saturation pressure is the median throat radius. It can approximately represent the average throat radius of the rock sample.

\section{(3) Radius mean and mainstream throat radius}

The average position of the full-hole roar distribution is called the mean radius. The smaller the average value, the smaller the average value of the total hole roar, indicating that the small pore throat is dominant in the entire hole roar, which is extremely unfavorable to oil and gas storage and seepage. The main flow throat radius refers to the throat radius when the cumulative contribution rate of the throat to the permeability reaches $80 \%$. It is an important parameter to characterize the micropore structure of the core of a lowpermeability tight reservoir and affects the seepage capacity of the reservoir fluid.

\section{(4) Sorting coefficient}

This is a measure of the standard deviation of the pore bellows size in the sample, and it directly reflects the concentration of the pore bellows distribution. In the total pores, when a certain level of pore bellows dominates, it indicates that the pores are well sorted. The smaller the $S_{\mathrm{p}}$ value, the more uniform the pore distribution

$S_{\mathrm{p}}=\frac{\psi_{84}-\psi_{16}}{4}+\frac{\psi_{95}-\psi_{5}}{6.6}$

where $\psi_{i}$ represents the value of $\psi$ corresponding to the cumulative mercury saturation of $i \%$ on the normal probability curve. The calculation formula $\psi$ is as follows:

$\psi=-\log _{2} D_{i}=-\log _{2} 2 R_{i}$

where $D_{i}$ is the pore throat diameter of the $i$ point $(\mu \mathrm{m}) ; R_{i}$ is the pore throat radius of the $i$ point $(\mu \mathrm{m})$.

\section{(5) Maximum intrusive mercury saturation}

The maximum mercury saturation indicates the percentage of pore volume that mercury enters when the injection pressure reaches the maximum pressure of the instrument. The larger the value, the more throats of the larger pores of the rock and the better the reservoir performance.

\section{(6) Mercury removal efficiency}

Mercury removal saturation refers to the ratio of the volume of mercury that exits to the total pore volume of the rock sample after the maximum injection pressure is reduced to the minimum mercury removal pressure. The mercury removal efficiency is the ratio of the mercury removal saturation to the maximum mercury saturation, and its size is not only related to the mercury removal saturation, but also the maximum mercury saturation. Mercury removal efficiency is a parameter that reflects the connectivity of pores and throats and controls the characteristics of fluid movement and, to a certain extent, characterizes the influence of pore structure heterogeneity on recovery. It corresponds to the non-wetting phase capillary effect recovery factor, which is equivalent to strong hydrophilicity. 
Table 3 shows the experimental data of high-pressure mercury intrusion in the four cores of shale oil reservoirs. The experimental data show that: (1) the maximum intrusive mercury saturation of the four cores is above $80 \%$, and the average maximum intrusive mercury saturation is $87.98 \%$, exceeding the high-pressure intrusive mercury saturation in the general shale gas reservoir core. The majority of throats and pores of the reservoir cores are within the test range; (2) the average displacement pressure is $3.98 \mathrm{MPa}$, which is more than twice that of the general tight sandstone reservoir, indicating that the mainstream pore throat radius of the shale oil layer is small; (3) there is a positive correlation between the main throat radius and the permeability, indicating that the large pore throat has an important influence on the permeability.

Figure 3 shows that the permeability has a strong positive correlation with the maximum pore throat radius and the sorting coefficient, i.e., the correlation coefficients are 0.82 and 0.83 , and there is a weak positive correlation with the median radius, i.e., the correlation coefficient is 0.71 . There

Table 3 Experimental data of high-pressure mercury intrusion in cores

\begin{tabular}{|c|c|c|c|c|c|c|c|c|c|}
\hline No. & $\begin{array}{l}\text { Displace- } \\
\text { ment pres- } \\
\text { sure }\end{array}$ & $\begin{array}{l}\text { Max pore } \\
\text { throat } \\
\text { radius }\end{array}$ & Median pressure & Median radius & Radius mean & $\begin{array}{l}\text { Mainstream } \\
\text { throat radius }\end{array}$ & $\begin{array}{l}\text { Sorting } \\
\text { coeffi- } \\
\text { cient }\end{array}$ & $\begin{array}{l}\text { Maximum intru- } \\
\text { sive mercury sat- } \\
\text { uration }\end{array}$ & $\begin{array}{l}\text { Mer- } \\
\text { cury removal effi- } \\
\text { ciency }\end{array}$ \\
\hline l & $\mathrm{MPa}$ & $\mu \mathrm{m}$ & $\mathrm{MPa}$ & $\mu \mathrm{m}$ & $\mu \mathrm{m}$ & $\mu \mathrm{m}$ & I & $\%$ & $\%$ \\
\hline 1 & 5.50 & 0.13 & 7.71 & 0.095 & 12.33 & 0.13 & 0.79 & 81.92 & 45.12 \\
\hline 2 & 1.35 & 0.54 & 6.24 & 0.118 & 11.76 & 0.54 & 1.13 & 81.61 & 41.49 \\
\hline 3 & 3.58 & 0.21 & 13.96 & 0.050 & 13.19 & 0.09 & 0.80 & 91.82 & 48.09 \\
\hline 4 & 5.50 & 0.13 & 8.29 & 0.089 & 12.58 & 0.09 & 0.72 & 96.56 & 47.10 \\
\hline
\end{tabular}

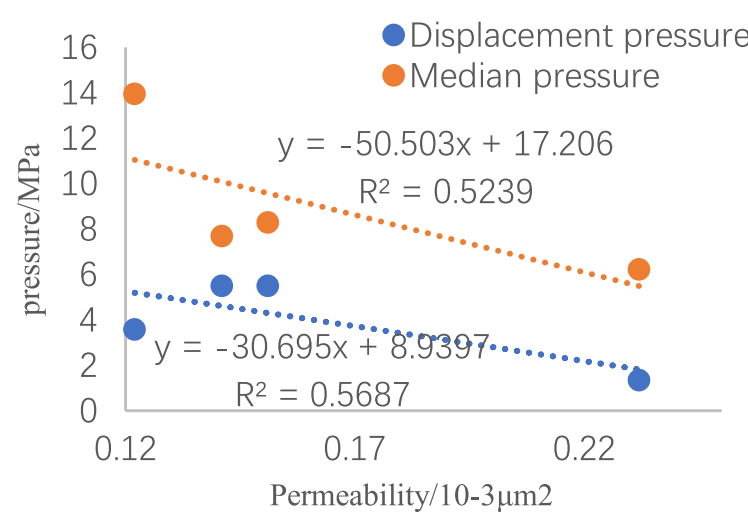

(a)

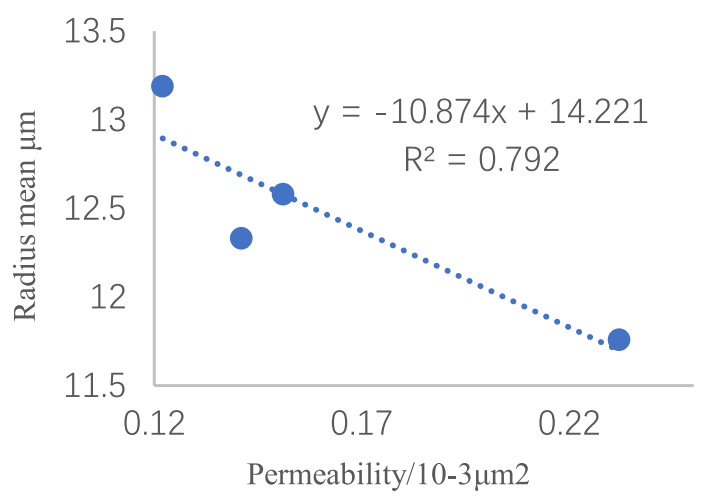

(c)

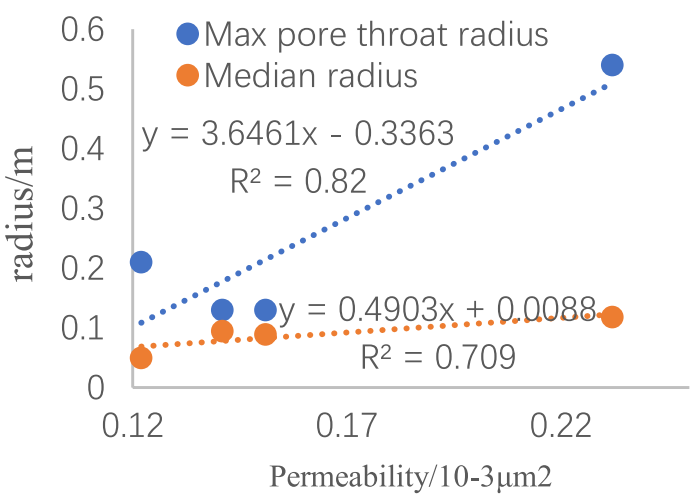

(b)

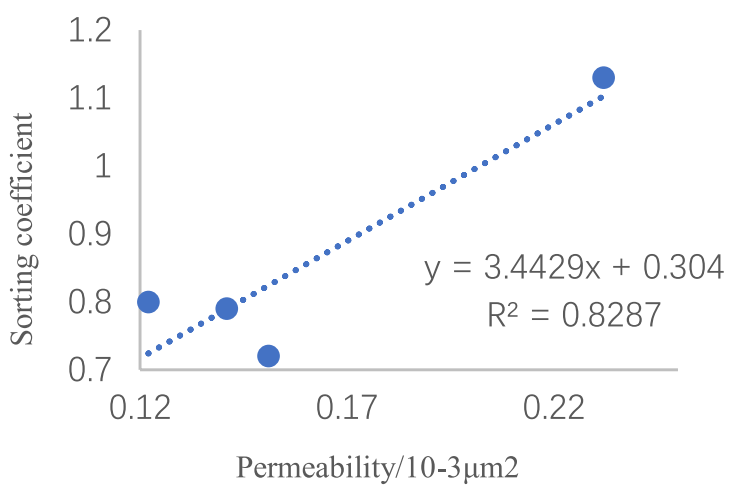

(d)

Fig. 3 Relationship between permeability and experimental results parameters 
is a weak negative correlation with displacement pressure, median pressure, and radius mean, with correlation coefficients of $0.57,0.52$, and 0.79 . The larger the permeability, the larger the maximum pore radius, median radius, and sorting coefficient, and the smaller the displacement pressure, median pressure, and radius mean.

Figure 4 shows that the porosity has a strong positive correlation with the displacement pressure, i.e., the correlation coefficient is 0.99 , and there is a strong negative correlation with the maximum pore throat radius and the sorting coefficient, i.e., the correlation coefficient is 0.93 and 0.84 , and there is no correlation with median pressure, median radius, and radius mean.

The capillary pressure curve and the pore throat radius volume frequency distribution histogram of the four cores are shown in Figs. 5 and 6. The shapes of the capillary pressure curves of the four cores are similar, and the middle flat section is relatively long. This is consistent with the peak concentration in the histogram of the pore throat volume and frequency distribution, indicating that the development of core pore throat is single and the size is concentrated and continuous, mainly distributed at an interval of $30-500 \mathrm{~nm}$.

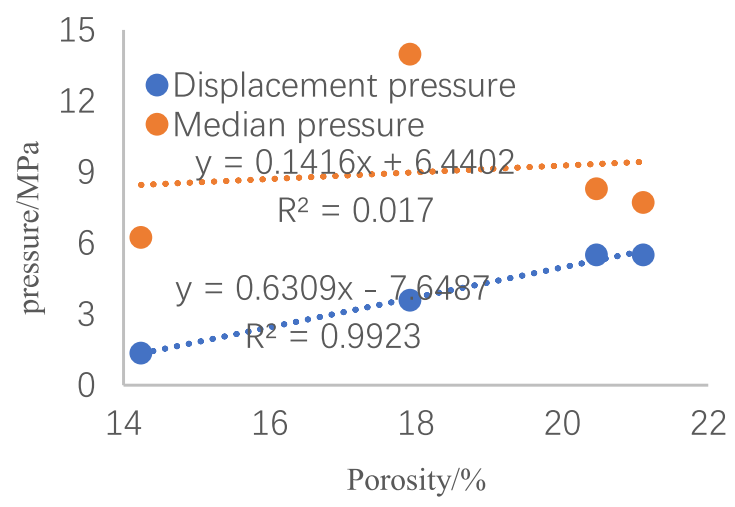

(a)

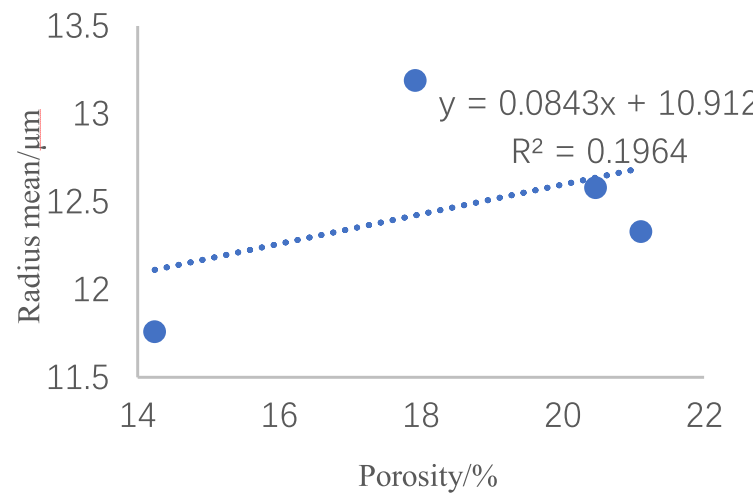

(c)
The intrusive mercury saturation of the four cores is divided according to the interval of different pore throat radii, as shown in Table 4 and Fig. 7, showing that: (1) the ratio of pores with a radius of $10-500 \mathrm{~nm}$ is $81.25 \%$, $76.49 \%, 89.39 \%$, and $95.52 \%$, and the average is 85.67 . The average pores with a radius of less than $500 \mathrm{~nm}$ are $86.87 \%$, indicating that the pores below $500 \mathrm{~nm}$ in this rock sample are very developed. (2) The core pore space of the No. 1 core is relatively high, and the submicron pore space of No. 2 core is relatively high. The main pore space is controlled by the pore throat of $0.05-0.5 \mu \mathrm{m}$. The nano-porosity space accounts for a higher proportion for No. 3 and No. 4 cores and is mainly controlled by a pore throat ranging from 0.01 to $0.1 \mu \mathrm{m}$. (3) Only No. 2 core contains less than $5 \%$ of pores with a radius greater than $500 \mathrm{~nm}$, and large pores are extremely underdeveloped. Large-scale hydraulic fracturing should be considered when development.

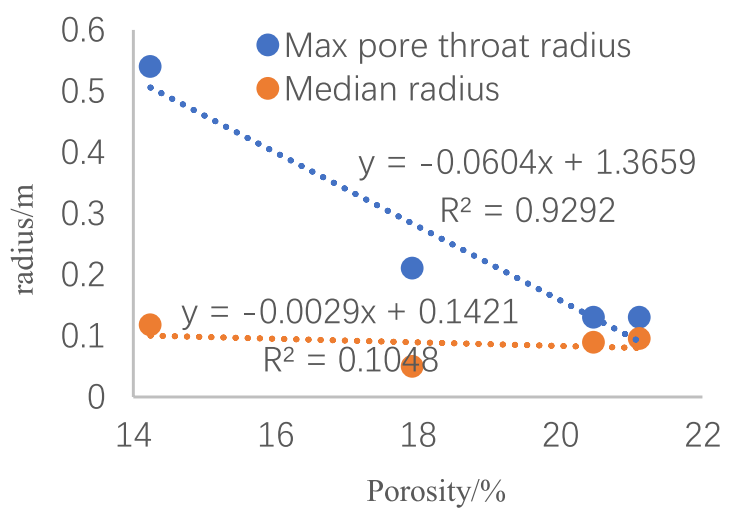

(b)

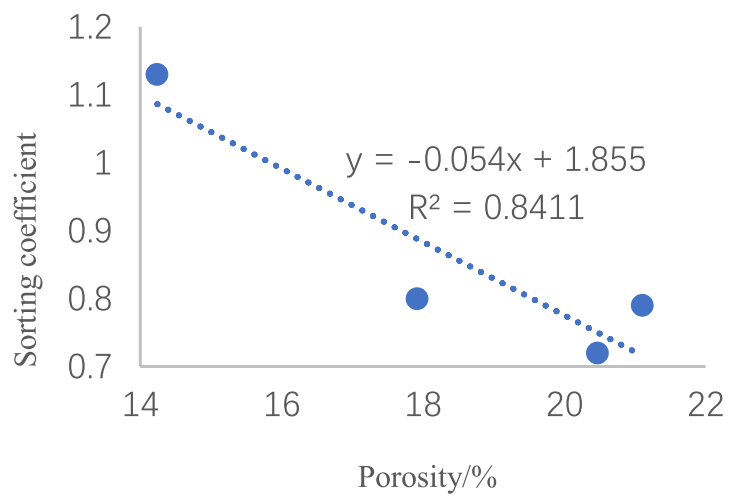

(d)

Fig. 4 Relationship between porosity and experimental results parameters 

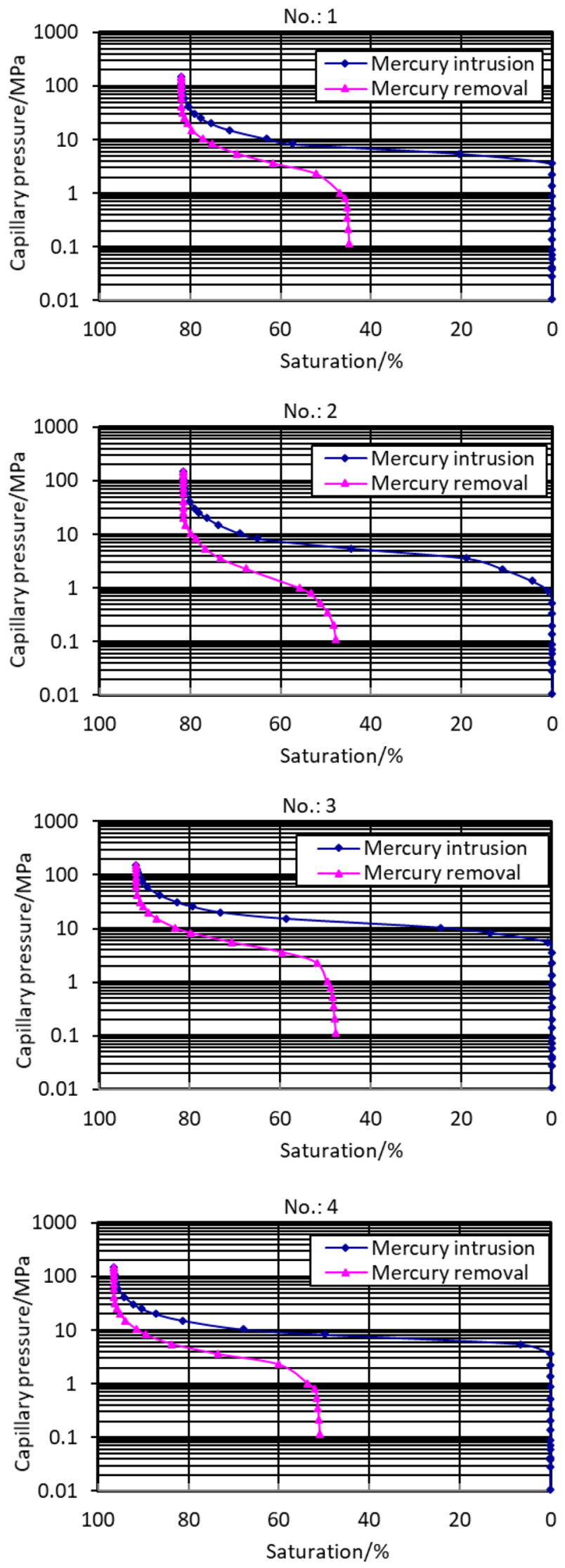

Fig. 5 Capillary pressure curves of four cores

\section{Comparison of pore distribution between shale oil reservoirs and typical tight sandstone reservoirs}

Tight sandstone reservoirs have achieved great development results in China. To learn from the development experience and inspiration, we selected the cores from the tight oil reservoirs of the two basins that had achieved good development results in China, which have similar permeability to the rock oil reservoirs for high-pressure mercury intrusion experiment. The lithology and mineral composition of these three cores are listed in Table 5, and the pore throat radius distribution curve is shown in Fig. 8.

The three cores have similar permeability, and the mainstream throat radius increases in the order of shale oil reservoir, Daqing tight sandstone reservoir, and Changqing tight sandstone reservoir. Due to the tight reservoir, the three cores are free of microporous throat development. Compared with the tight sandstones of Changqing and Daqing, the proportion of nanoporous throat in argillaceous shale is relatively large for comparable permeability, while the proportion of the submicron pore throat in the tight sandstone is relatively large. The maximum intrusive mercury saturation of the shale oil core has a small decrease compared with the tight sandstone, but it still reaches more than $80 \%$, indicating that the high-pressure mercury injection experiment is an effective method to study the microscopic pore structure of the shale oil reservoir.

\section{Fractal characteristics of micro-nano-pores in shale oil reservoirs and tight sandstone reservoirs}

Previous fractal studies on the pore structure of tight oil and shale gas reservoirs show that they have good fractal characteristics (Lin et al. 2017, 2018; Wang et al. 2019). To quantitatively characterize the heterogeneity of shale reservoirs, we used fractal theory to quantitatively characterize the microscopic heterogeneity of shale oil and tight sandstone reservoirs. Fractal refers to the theory that some and all of the porous media had similarities in pore morphology, function, etc. This kind of self-similarity is only manifested on a certain scale. Many scholars have done a lot of fractal theory-related research on pore junctions in various formations. The specific methods are different; this method is not used alone. Different theories are mainly selected based on the characteristics of the experimental methods combined with them (Xiong et al. 2016). Based on the experimental basis of high-pressure mercury intrusion, this paper uses the fractal theory (Wu and Zhao 2017) to calculate the fractal dimension and quantitatively characterize its heterogeneity. In theory, as for threedimensional fractal objects the fractal dimension should be between 2 and 3 . The smaller the fractal dimension, the more regular the pore structure of the sample. The larger the fractal dimension, the more complex the pore structure of the sample. 
No.:1

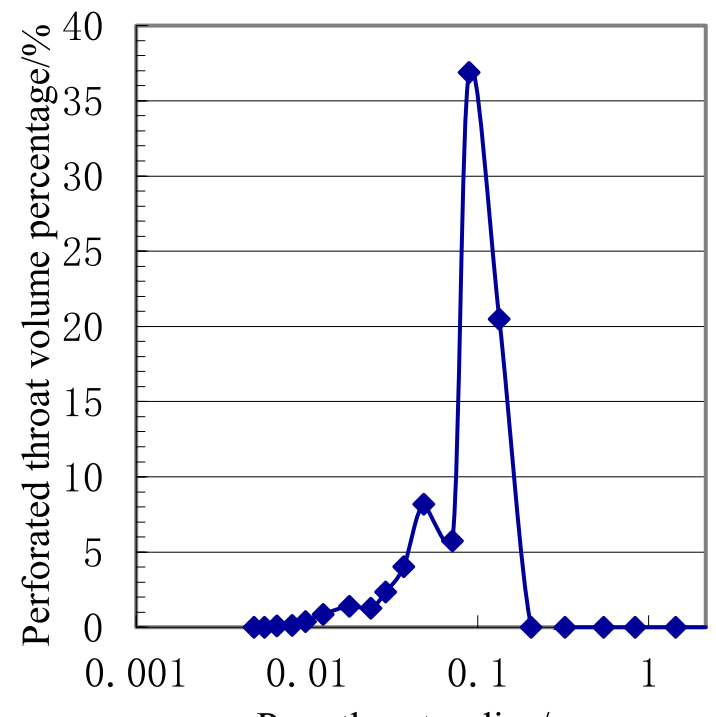

Pore throat radius $/ \mu \mathrm{m}$

No.:3

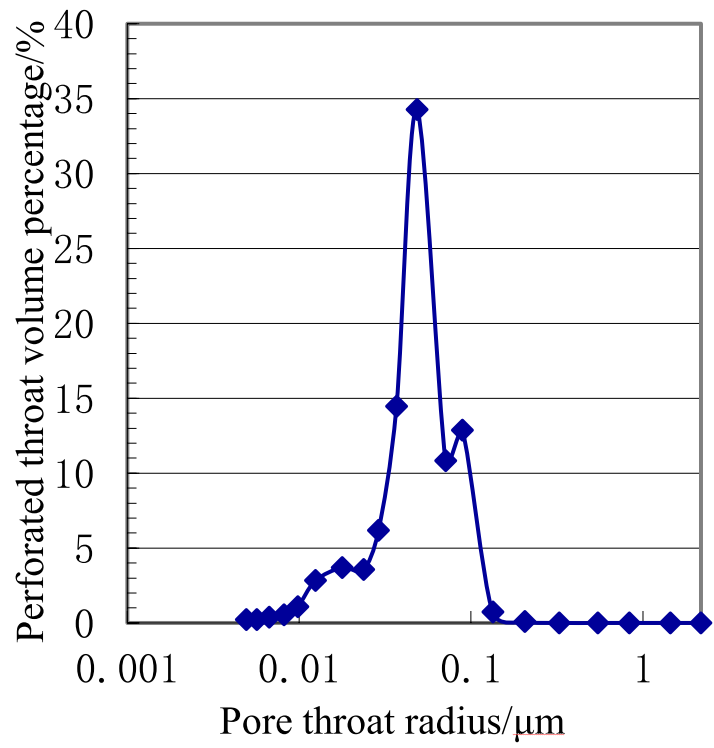

No.:2

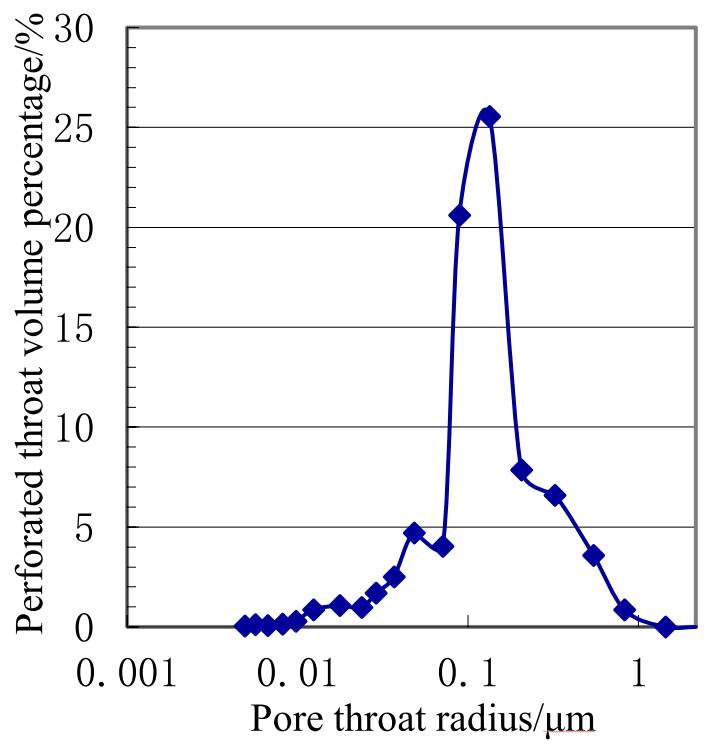

No.:4

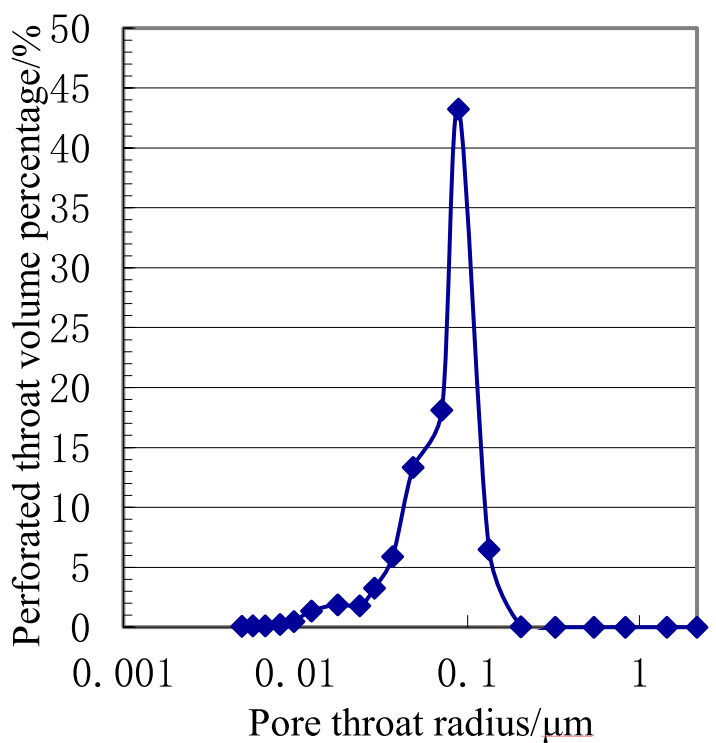

Fig. 6 Throat radius volume frequency distribution histogram of four cores

Table 4 Statistics of pore intrusive mercury saturation in different pore throat intervals of four cores

\begin{tabular}{llllllllll}
\hline No. & Porosity & Permeability & $\begin{array}{l}\text { Klinkenberg } \\
\text { permeability }\end{array}$ & & \multicolumn{2}{l}{$\begin{array}{l}\text { Pore intrusive mercury saturation controlled by different } \\
\text { pore throat radii }(\mu \mathrm{m}), \%\end{array}$} \\
\cline { 8 - 12 }$/$ & $\%$ & MD & $10^{-3} \mu \mathrm{m}^{2}$ & $<0.01$ & $0.01-0.05$ & $0.05-0.1$ & $0.1-0.5$ & $0.5-1$ & $>1$ \\
\hline 1 & 21.10 & 0.141 & 0.069 & 0.66 & 18.11 & 42.64 & 20.50 & 0 & 0 \\
2 & 14.24 & 0.232 & 0.165 & 0.68 & 11.83 & 24.66 & 40.00 & 3.59 & 0.85 \\
3 & 17.92 & 0.122 & 6.88 & 2.42 & 64.94 & 23.66 & 0.79 & 0 & 0 \\
4 & 20.47 & 0.151 & 0.074 & 1.05 & 27.58 & 61.38 & 6.56 & 0 & 0 \\
Mean & 18.44 & 0.162 & 0.092 & 1.20 & 30.62 & 38.09 & 16.96 & 1.20 & 0.21 \\
\hline
\end{tabular}




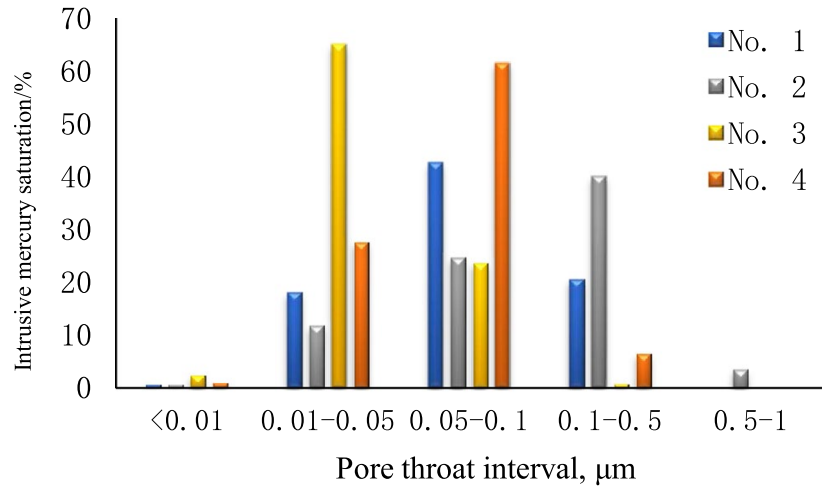

Fig. 7 Pore intrusive mercury saturation in different pore throat intervals

If it is less than 2 or greater than 3 , it has no fractal meaning (Cui et al. 2017).

The fractal geometry formula of the pore distribution can be written as (Ma et al. 2004):

$1-s=\left(\frac{p}{p_{\min }}\right)^{D-3}$.

The logarithm of both sides of Eq. (3) can be obtained:

$\ln (1-s)=(D-3) \ln (p)-(D-3) \ln \left(p_{\min }\right)$.

If $\ln (1-s)=y, \ln p=x, D-3=a$, then $y=a x-a b$. The fractal dimension $\mathrm{D}$ of the pore volume of shale oil cores can be obtained by fitting the slope $\mathrm{k}$ of the straight line in the $\ln (1-s)$ and $\ln (p)$ relationship diagrams.

Figure 9 shows a fractal diagram of four cores of shale oil reservoirs. The expressions are: $Y=-0.4306 X+0.0322$, $Y=-0.4674 X+0.0154, \quad Y=-0.4547 X+0.3078$, $Y=-0.4964 X+0.9817$. The correlation coefficients $R^{2}$ are $0.9376,0.9045,0.9261$, and 0.9109 , respectively, indicating that the micro-nano-pore fractal characteristics of shale oil reservoirs are obvious. Due to the use of different fractal theory formulas, the calculation of the fractal dimension is different, and its relative size can represent the heterogeneity of different reservoirs (Wu et al. 2016).

To clarify the fractal dimension characteristics of the shale oil reservoir, it is compared with the tight oil reservoirs of two typical basins; the results are shown in Table 6. It can be found that the micro-nano-pore fractal dimension of shale oil reservoirs is not much different and larger than the fractal dimension of the selected tight oil reservoir, indicating that its heterogeneity is stronger.

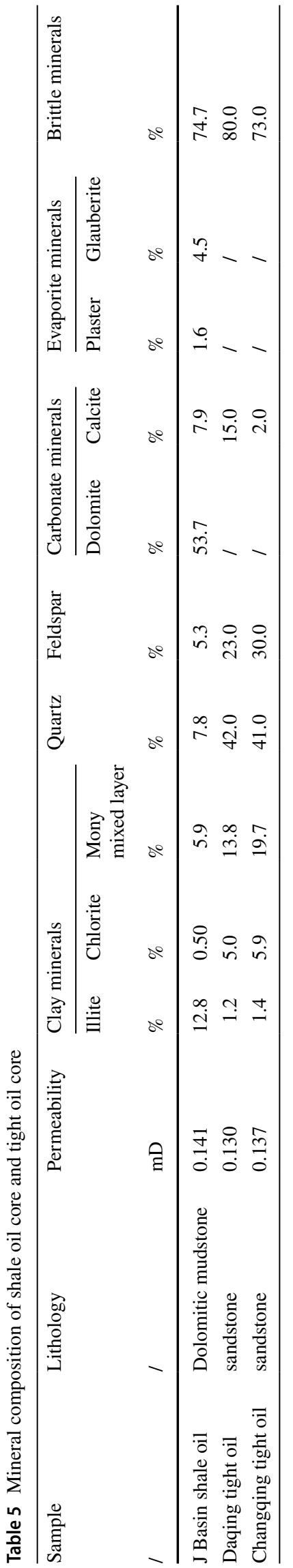




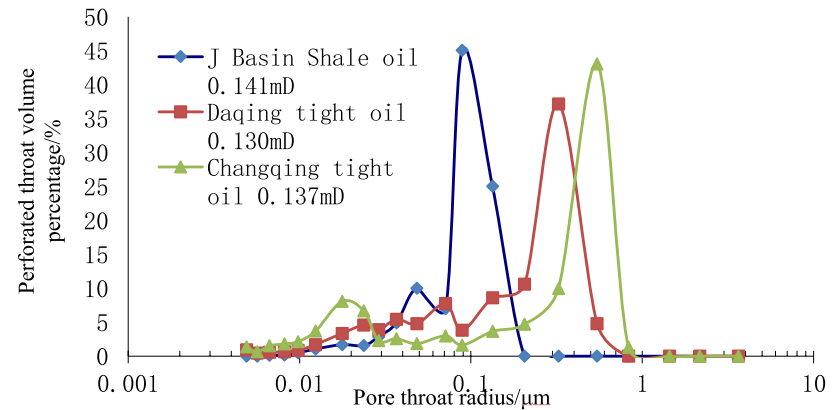

Fig. 8 Comparison of pore throat radius distribution of shale oil and tight oil

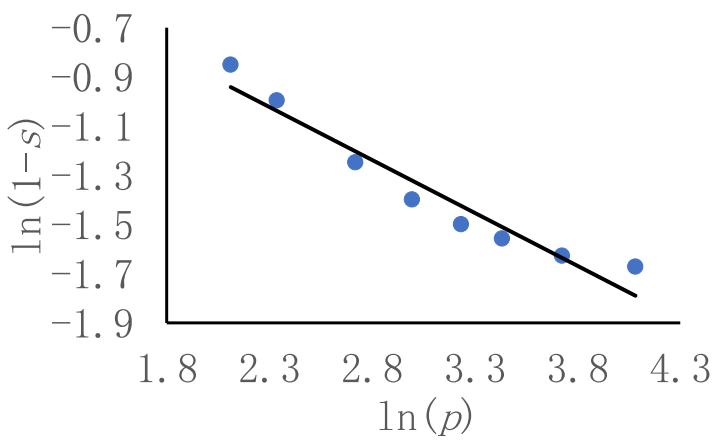

No. 1

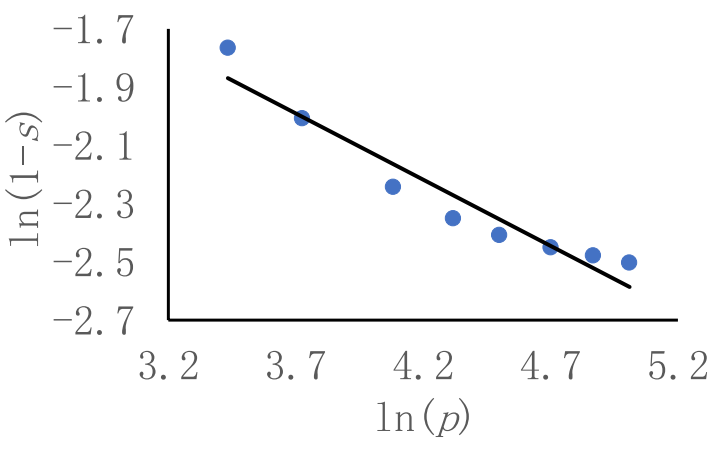

No. 3

\section{Conclusion}

Through the above study of the micro-nano-pore structure characteristics of shale oil reservoirs, the following conclusions can be drawn:

1. The shale oil reservoirs have poor porosity and permeability, and the heterogeneity is strong. The dolomitic development is conducive to the development of shale oil reservoir;

2. The permeability has a strong positive correlation with the maximum pore throat radius and the sorting coefficient, and there is a weak positive correlation with the median radius, and there is a weak negative correlation

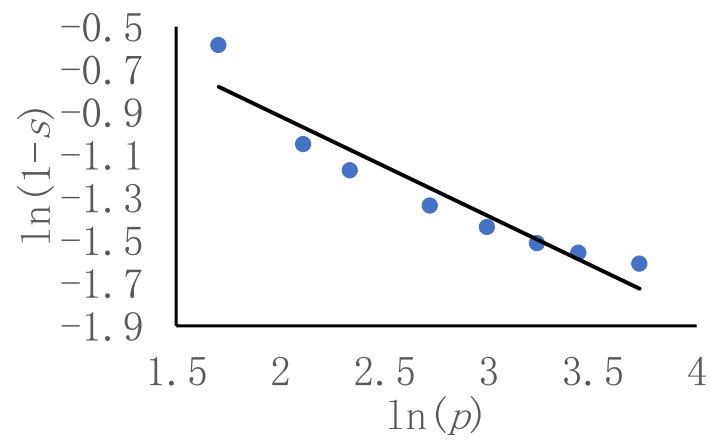

No. 2

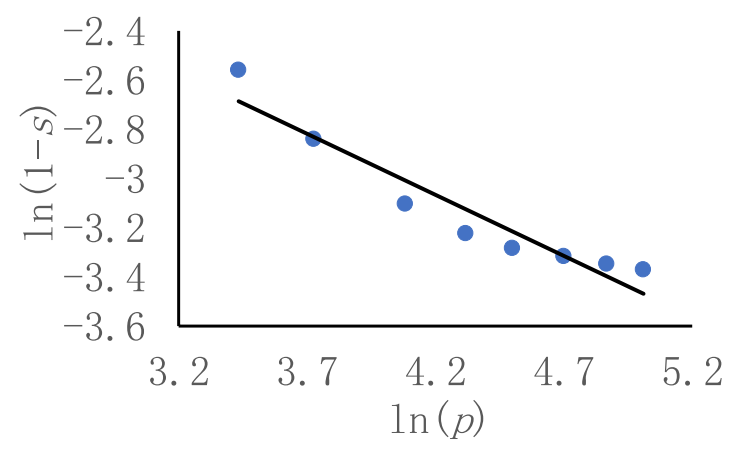

No. 4

Fig. 9 Fractal features of four cores

Table 6 Fractal dimension of cores of shale oil and typical tight oil reservoirs

\begin{tabular}{|c|c|c|c|c|c|c|c|c|}
\hline \multicolumn{3}{|c|}{ Shale oil reservoir } & \multicolumn{3}{|c|}{$\begin{array}{l}\text { Tight oil reservoir in Songliao } \\
\text { Basin }\end{array}$} & \multicolumn{3}{|c|}{ Tight oil reservoir in Ordos Basin } \\
\hline No. & Lithology & $\begin{array}{l}\text { Fractal } \\
\text { dimen- } \\
\text { sion }\end{array}$ & No. & Lithology & $\begin{array}{l}\text { Fractal } \\
\text { dimen- } \\
\text { sion }\end{array}$ & No. & Lithology & $\begin{array}{l}\text { Fractal } \\
\text { dimen- } \\
\text { sion }\end{array}$ \\
\hline 1 & Dolomitic mudstone & 2.57 & 1 & Tight sandstone & 2.39 & 1 & Tight sandstone & 2.23 \\
\hline 2 & Dolomitic mudstone & 2.53 & 2 & Tight sandstone & 2.33 & 2 & Tight sandstone & 2.20 \\
\hline 3 & Dolomitic mudstone & 2.55 & 3 & Tight sandstone & 2.35 & 3 & Tight sandstone & 2.24 \\
\hline 4 & Dolomitic mudstone & 2.50 & 4 & Tight sandstone & 2.33 & 4 & Tight sandstone & 2.22 \\
\hline
\end{tabular}


with displacement pressure, median pressure, and radius mean. The porosity has a strong positive correlation with the displacement pressure, and there is a strong negative correlation with the maximum pore throat radius and the sorting coefficient, and there is no correlation with median pressure, median radius, and radius mean.

3 . The pore throat size of the shale oil reservoir is concentrated and continuous with good pore connectivity. The main distribution range of pore radius is $30-500 \mathrm{~nm}$, and the large pore throat has a major influence on the permeability;

4. In case of comparable permeability, the proportion of nano-throats is relatively large in the shale oil reservoirs, while the proportion of the submicron pore throats in the tight sandstone is relatively large;

5. The fractal dimension of the shale oil reservoir is significantly larger than that of a typical tight oil reservoir, indicating that its heterogeneity is stronger.

Acknowledgements The authors gratefully acknowledge financial support from the National Science and Technology Major Project (2017ZX05049005-004), National Science and Technology Major Project "Key Technologies for Effective Development of Low Permeability-Ultra-low Permeability Reservoirs" (2017ZX05013-001), and National Science and Technology Major Demonstration Project "Tight Oil Seepage Characteristics and Development Optimization Research and Application" (2017ZX05069003).

Data availability The data used to support the findings of this study are available from the corresponding author upon request.

\section{Compliance with ethical standards}

Conflict of interest The authors declared that they have no conflicts of interest in this work.

Open Access This article is licensed under a Creative Commons Attribution 4.0 International License, which permits use, sharing, adaptation, distribution and reproduction in any medium or format, as long as you give appropriate credit to the original author(s) and the source, provide a link to the Creative Commons licence, and indicate if changes were made. The images or other third party material in this article are included in the article's Creative Commons licence, unless indicated otherwise in a credit line to the material. If material is not included in the article's Creative Commons licence and your intended use is not permitted by statutory regulation or exceeds the permitted use, you will need to obtain permission directly from the copyright holder. To view a copy of this licence, visit http://creativecommons.org/licenses/by/4.0/.

\section{References}

Bai B, Zhu R, Wu S, Yang W, Jeff G, Allen G, Zhang X, Su L (2013) Multi-scale method of nano (micro)-CT study on microscopic pore structure of tight sandstone of Yanchang Formation, Ordos Basin. Pet Explor Dev 40(03):329-333
Butcher AR, Lemmens HJ (2011) Advanced SEM technology clarifies nanoscale properties of gas accumulations in shales. Am Oil Gas Rep 54(11):118-124

Chen S, Zhao W (2010) Characterization of inter-salt argillaceous dolomite reservoirs in Qianjiang Depression, Jianghan Basin. J Yangtze Univ Nat Sci Edn 7(1):168-170

Chen T, Yang Z, Ding Y, Luo Y, Qi D, Lin W, Zhao X (2018) Waterflooding huff-n-puff in tight oil cores using online nuclear magnetic resonance. Energies 11(6):1524. https://doi.org/10.3390/ en11061524

Clarkson CR, Solano N, Bustin RM, Bustin AMM, Chalmers GRL, He L et al (2013) Pore structure characterization of North American shale gas reservoirs using USANS/SANS, gas adsorption, and mercury intrusion. Fuel 103:606-616. https://doi.org/10.1016/j. fuel.2012.06.119

Cui Y, Xiong W, Zuo L, Gao S, Hu Z (2017) Research on full-scale pore size distribution characteristics of shale and corresponding test methods. Bull Sci Technol 33(11):34-38. https://doi. org/10.13774/j.cnki.kjtb.2017.11.009

Curtis ME, Ambrose RJ, Sondergeld CH (2010) Structural characterization of gas shales on the micro-and nano-scales. In: Canadian unconventional resources and international petroleum conference. Society of Petroleum Engineers. https://doi.org/10.2118/13769 3-MS

Demaison GJ, Moore GT (1980) Anoxic environments and oil source bed genesis. Org Geochem 2(1):9-31. https://doi. org/10.1016/0146-6380(80)90017-0

Didar BR, Akkutlu IY (2013) Pore-size dependence of fluid phase behavior and properties in organic-rich shale reservoirs. In: SPE international symposium on oilfield chemistry. Society of Petroleum Engineers. https://doi.org/10.2118/164099-MS

Fishman NS, Hackley PC, Lowers HA, Hill RJ, Egenhoff SO, Eberl DD, Blum AE (2012) The nature of porosity in organic-rich mudstones of the Upper Jurassic Kimmeridge clay formation, North Sea, offshore United Kingdom. Int J Coal Geol 103:32-50. https ://doi.org/10.1016/j.coal.2012.07.012

Gong Y, Liu S, Zhu R, Liu K, Tang Z, Jiang L (2015) Lower limit of tight oil flowing porosity: application of high-pressure mercury intrusion in the fourth Member of Cretaceous Quantou Formation in southern Songliao Basin, NE China. Pet Explor Dev 42(5):745752. https://doi.org/10.1016/S1876-3804(15)30071-9

Guo H, Liu Q, Li H, Meng Z, Bai Y (2013) Microstructural characteristics of the Jurassic tight oil reservoirs in Sichuan Basin. J Shenzhen Univ Sci Eng 30(03):306-312. https://doi.org/10.3724/ SP.J.1249.2013.03306

Jarvie DM, Hill RJ, Ruble TE, Pollastro RM (2007) Unconventional shale-gas systems: the Mississippian Barnett Shale of north-central Texas as one model for thermogenic shale-gas assessment. AAPG Bull 91(4):475-499

Jia C, Zou C, Li J, Li D, Zheng M (2012) Assessment criteria, main types, basic features and resource prospects of the tight oil in China. Acta Petrolei Sinica 33(03):343-350

Katz A, Thompson AH (1985) Fractal sandstone pores: implications for conductivity and pore formation. Phys Rev Lett 54(12):1325. https://doi.org/10.1103/PhysRevLett.54.1325

Kou R, Alafnan SFK, Akkutlu IY (2016) Coupling of Darcy's equation with molecular transport and its application to upscaling kerogen permeability. In: SPE Europec featured at 78th EAGE conference and exhibition. Society of Petroleum Engineers. https://doi. org/10.2118/180112-ms

Krohn CE (1988) Fractal measurements of sandstones, shales, and carbonates. J Geophys Res Solid Earth 93(B4):3297-3305. https:// doi.org/10.1029/JB093iB04p03297

Kuila U, Prasad M (2013) Specific surface area and pore-size distribution in clays and shales. Geophys Prospect 61(2):341-362. https ://doi.org/10.1111/1365-2478.12028 
Labani MM, Rezaee R, Saeedi A, Al Hinai A (2013) Evaluation of pore size spectrum of gas shale reservoirs using low pressure nitrogen adsorption, gas expansion and mercury porosimetry: a case study from the Perth and Canning Basins, Western Australia. J Petrol Sci Eng 112:7-16. https://doi.org/10.1016/j.petrol.2013.11.022

Li H, Zhu J, Guo H (2008) Methods for calculating pore radius distribution in rock from NMR T2 spectra. Chin J Magn Reson 2:273-280

Li J, Zheng M, Chen X, Hua D, Wang S, Song T (2015) Connotation analyses, source-reservoir assemblage types and development potential of unconventional hydrocarbon in China. Acta Petrolei Sinica 36(05):521-532. https://doi.org/10.7623/syxb201505001

Lin W, Yang Z, Li X, Wang J, He Y, Wu G et al (2017) A method to select representative rock samples for digital core modeling. Fractals 25(04):1740013. https://doi.org/10.1142/S0218348X1 7400138

Lin W, Li X, Yang Z, Lin L, Xiong S, Wang Z et al (2018) A new improved threshold segmentation method for scanning images of reservoir rocks considering pore fractal characteristics. Fractals 26(02):1840003. https://doi.org/10.1142/S0218348X18400030

Liu B, Yao S, Hu W, Cao J, Xie D (2017) Applicability of NMR freezethaw method for characterizing pores in unconventional oil and gas reservoirs. Acta Petrolei Sinica 38(12):1401-1410

Loucks RG, Reed RM, Ruppel SC, Jarvie DM (2009) Morphology, genesis, and distribution of nanometer-scale pores in siliceous mudstones of the Mississippian Barnett Shale. J Sediment Res 79(12):848-861. https://doi.org/10.2110/jsr.2009.092

Ma X, Zhang S, Lang Z (2004) Calculation of fractal dimension of pore structure by using subsection regression method. J Univ Petrol 06:54-56

Shen W, Song F, Hu X, Zhu G, Zhu W (2019) Experimental study on flow characteristics of gas transport in micro-and nanoscale pores. Sci Rep 9(1):1-10. https://doi.org/10.1038/s41598-019-46430-2

Sing KS (1985) Reporting physisorption data for gas/solid systems with special reference to the determination of surface area and porosity (recommendations 1984). Pure Appl Chem 57(4):603619. https://doi.org/10.1351/pac198557040603

Slatt RM, O'Brien NR (2011) Pore types in the Barnett and Woodford gas shales: contribution to understanding gas storage and migration pathways in fine-grained rocks. AAPG Bull 95(12):20172030. https://doi.org/10.1306/03301110145

Sun Z, Lu X, Jia X (2017) Optimization of mercury intrusion capillary pressure measurement for characterizing the pore structure of tight rocks. J Nanosci Nanotechnol 17(9):6242-6251

Wang H, Ma F, Tong X, Liu Z, Zhang X, Wu Z, Li D, Wang B, Xie Y, Yang L (2016) Assessment of global unconventional oil and gas resources. Pet Explor Dev 43(06):850-862. https://doi. org/10.11698/PED.2016.06.02

Wang Z, Yang Z, Ding Y, He Y, Lin W, Wang W, Sheng G (2019) A multi-linear fractal model for pressure transient analysis of multiple fractured horizontal wells in tight oil reservoirs including imbibition. Fractals 27(01):1940004. https://doi.org/10.1142/ S0218348X19400048

Washburn EW (1921) A note on the method of determining the distribution of pore sizes in a porous material. Proc Natl Acad 116:155

Wei W, Cai J, Hu X, Fan P, Han QI, Lu J et al (2015) A numerical study on fractal dimensions of current streamlines in two-dimensional and three-dimensional pore fractal models of porous media. Fractals 23(01):1540012. https://doi.org/10.1142/S0218348X154001 25

Wu J, Zhao L (2017) Fractal features of Longtan formation coal reservoir in Liupanshui on the mercury injection method. Sichuan Chem Ind 20(01):28-30

Wu S, Tang X, Du X, Liang W, He Q (2013) Geologic characteristics of continental shale oil in the Qianjiang Depression, Jianghan Salt Lake Basin. J East China Univ Technol (Natural Science) 36(03):282-286

Wu J, Liang F, Lin W, Wei C, Song S (2016) Characteristics of micropore structure of Longmaxi Formation shale gas reservoirs in northeast district of Chongqing, China. J Chengdu Univ Technol (Science \& Technology Edition) 43(03):308-319

Xiong J, Luo D, Liu X, Liang L (2016) Characteristics and controlling factors of shale pore structure of Yanchang Formation in Ordos Basin. Lithol Reserv 28(02):16-23. https://doi.org/10.3969/j. issn.1673-8926.2016.02.003

Yang F, Ning Z, Hu C, Wang B, Peng K, Liu H (2013) Characterization of microscopic pore structures in shale reservoirs. Acta Petrolei Sinica 34(02):301-311

Zhang M, Li X, Dong Z, Guo M, Sun M, Fan J (2015) Analyses on mineral compositions and brittleness of the lower Cambrian Hetang Formation shale in south Anhui province. Bull Mineral Petrol Geochem 34(1):177-183

Zhao P, Li X, Sun J, Lai S, Fu T, Su G, Tian X (2014) Study on mineral composition and brittleness characteristics of shale gas reservoirs from the lower Paleozoic in the southern Sichuan Basin. Geoscience 28(2):396-403

Zhao X, Yang Z, Lin W, Xiong S, Luo Y, Wang Z et al (2019) Study on pore structures of tight sandstone reservoirs based on nitrogen adsorption, high-pressure mercury intrusion, and rate-controlled mercury intrusion. J Energy Res Technol 141(11):112903. https ://doi.org/10.1115/1.4043695

Zhong T (2012) Characteristics of pore structure of marine shales in South China. Nat Gas Ind 32(9):1-4

Zhu R, Bai B, Cui J, Wu S, Cui J, Wang T, Niu L, Li T (2013) Research advances of microstructure in unconventional tight oil and gas reservoirs. J Palaeogeogr 15(05):615-623. https://doi.org/10.7605/ gdlxb.2013.05.049

Zou C, Yang Z, Tao S, Li W, Wu S, Hou L, Zhu R, Yuan X, Wang L, Gao X, Jia J, Guo Q, Bai B (2012a) Nano-hydrocarbon and the accumulation in coexisting source and reservoir. Pet Explor Dev 39(01):13-26

Zou C, Zhu R, Wu S, Yang Z, Tao S, Yuan X, Hou L, Yang H, Xun C, Li D, Bai B, Wang L (2012b) Types, characteristics, genesis and prospects of conventional and unconventional hydrocarbon accumulations: taking tight oil and tight gas in China as an instance. Acta Petrolei Sinica 33(02):173-187

Publisher's Note Springer Nature remains neutral with regard to jurisdictional claims in published maps and institutional affiliations. 